\title{
Continuous Production of Glycerol by Catalytic High Pressure Hydrogenolysis of Sucrose
}

\author{
Gerrit Van Ling ${ }^{1}$, Alfons J. Driessen ${ }^{2}$, Arie C. Piet ${ }^{3}$, and Jozef C. Vlugter \\ Department of Chemical Engineering, Technological University "Twente," Enschede, Netherlands
}

\begin{abstract}
Several continuous reactor systems have been discussed for the catalytic high pressure hydrogenolysis of sucrose to glycerol. Theoretically and actually, continuous reactors lead to lower glycerol yields than in a batch process. Two continuous stirred tank reactors in cascade constitute a reasonable compromise. An economic evaluation of the sucrose route to glycerol in comparison with other synthetic glycerol processes based on allyl chloride and acrolein suggests that the sucrose process can be competitive if a sales potential is developed for the by-products propane-1,2-diol, ethylene glycol, and a mixture of higher polyhydric alcohols containing tetritol, pentitol, methyl fructoside, and hexitol.
\end{abstract}

\begin{abstract}
A hydrogenolysis of saccharides is an interesting route to the production of polyhydric alcohols, particularly glycerol, ethylene glycol, propane-1,2-diol, and hexitols. In a series of batch experiments Van Ling and Vlugter (1969) proved that, starting from sucrose, by selecting the proper reaction conditions to optimize the so-called hydrogenation selectivity (HS) and the cleavage percentage (CP), yields of 40 weight $\%$ glycerol could be obtained.

On the basis of the information obtained from batch experiments, we designed a pilot plant for the continuous production of glycerol. For the reactor system we had a choice of a tubular reactor (TR) or one or more continuous stirred tank reactors in cascade (CSTR).

Both systems give low glycerol yields, compared with a batch reactor. In a tubular reactor, to maintain plug flow, intensive mixing for maximum hydrogen mass transport is impossible. Hence a low hydrogenation selectivity can be expected. In a CSTR, the reactor mixture is the same as the product. Three undesirable consequences are:

The presence of lactic acid formed during hydrogenolysis causes an accelerated hydrolysis of sucrose to glucose and fructose, resulting in a lower cleavage percentage.

The exit concentration of $\mathrm{Ca}(\mathrm{OH})_{2}$ is lower than in a batch reactor. Since $\mathrm{Ca}(\mathrm{OH})_{2}$ promotes cleavage of the carbon chain of the saccharides, cleavage percentage decreases.

The residence time distribution in CSTR runs increases the conversion of glycerol to propane-1,2-diol, thereby decreasing hydrogenation selectivity.

\section{Experimental}

Exploratory experiments with sucrose were conducted with a TR and a CSTR. The TR consisted of a 2-meter

\footnotetext{
${ }^{1}$ Present address, Farbwerke Hoechst, Gersthofen, West Germany

${ }^{2}$ Present address, B.I.P.M. N.V., 's-Gravenhage, Netherlands

${ }^{3}$ Present address, Koninklijke/Shell Laboratorium, Amsterdam, Netherlands
}

stainless steel tube with a diameter of $2 \mathrm{~cm}$., filled with $1 / 8$-inch Raschig rings to promote good gas-liquid contact. Notwithstanding this precaution, strong decomposition of the sucrose occurred and glycerol yield ( $<20$ weight \%) was very poor.

The definitive pilot plant (Figure 1) was based on two CSTR's in cascade. This reactor system was a good compromise, in order to reduce the residence time distribution and to ensure complete conversion of sucrose. Each reactor had a total volume of $500 \mathrm{ml}$. and an operating volume of $250 \mathrm{ml}$. Catalyst $\left(\mathrm{CuO}-\mathrm{CeO}_{2}-\mathrm{SiO}_{2}\right)$, hydrogen, and sucrose (in methanol-water $75: 25 \mathrm{w} . / \mathrm{w}$.) were continuously fed into reactor $A$. The exit flow passed into reactor $B$, and the finished product then passed into a 1000ml. separator. Each reactor was provided with three baffles and equipped with an electromagnetically driven fourbladed turbine stirrer ( $n=1400$ r.p.m.).

\section{Results and Discussion}

Several experiments, described by Van Ling (1967), were carried out in this pilot plant. Uncolored reaction products with maximum glycerol yields up to 30 weight $\%$ were obtained at the reaction conditions listed in Table I. The product composition of this run is plotted in Table II.

Figure 2 compares the continuous and batch catalytic hydrogenolysis of sucrose, using parameters HS and CP. These parameters are lower in the CSTR system than in a batch reactor, resulting in lower glycerol yields.

As expected, the poor mixing of the reactants in the $T R$ results in an inadequate transport of hydrogen to the catalyst surface. Hence, the unstable triose intermediates, formed during the hydrogenolysis, decompose to undesired products, such as methylglyoxal, acetol, lactic acid, and propane-1,2-diol. A brown, charred product results and $\mathrm{HS}$ is low.

If, in general, the hydrogen mass transfer is described as

$$
N=K S C_{\mathrm{H}_{2}}(1-z)
$$




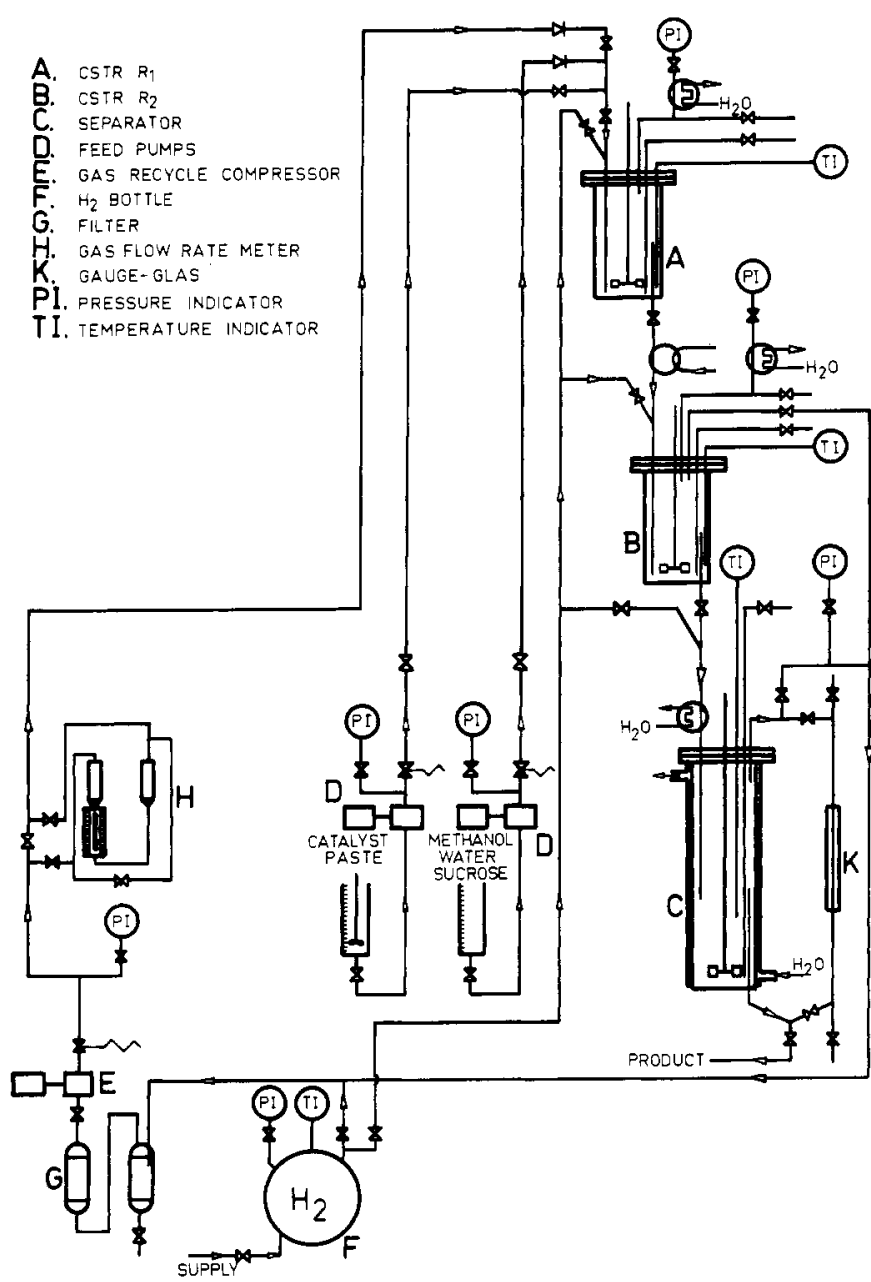

Figure 1. Pilot plant for continuous catalytic hydrogenolysis of sucrose

apparently, for a good hydrogenolysis reaction, $z$-i.e., the relative saturation of liquid near the catalyst surfacehas to be approximately 1 .

With physical absorption experiments in the CSTR system, at $200 \mathrm{~atm}$. and $225^{\circ} \mathrm{C}$., we have measured average $K S$ values of $8 \times 10^{-2} \mathrm{sec}^{-1}$ and a $C_{\mathrm{H}_{2}}$ value of 1.7 \pm 0.2 kmoles meter ${ }^{-3}$. From the hydrogenolysis experiments we have calculated that, according to the requirement for $z, K S$ must be $\gg 2 \times 10^{-3} \mathrm{sec}^{-1}$.

A second indication for a sufficient hydrogen mass transport in the CSTR system is shown in Figure 3. It appears that the HS of glucose and fructose is about the same as that of glycerol. This indicates a quantitative hydrogenation of the triose intermediates at pressures $\geqq 200$ atm. and the consecutive reaction of the formed glycerol into propane-1,2-diol to the same conversion rate as for glycerol itself.

We conclude that in the CSTR system the hydrogen mass transport is not a rate-determining factor.

Patents that describe the continuous catalytic hydrogenolysis of sucrose in a TR (Atlas Chemical Industries, 1964; Inventa A. G., 1962, 1967) seem discussible.

\section{Economic Aspects}

The laboratory process data have been economically evaluated by Driessen (1968). The study involved four alternative processes for the manufacture of glycerol: from sucrose by hydrogenolysis; from propylene via allyl chlo-

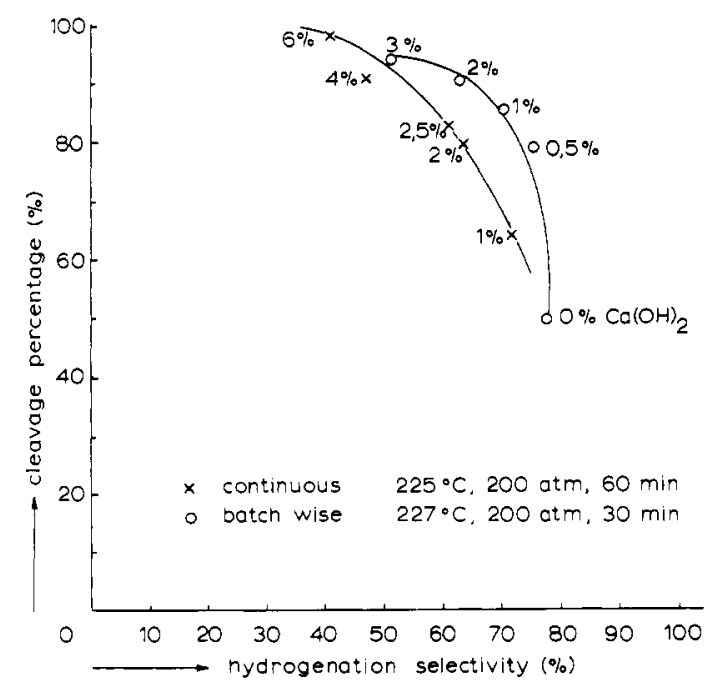

Figure 2. Results of continuous and batch catalytic hydrogenolysis of sucrose at varying $\mathrm{Ca}(\mathrm{OH})_{2}$ percentages

\begin{tabular}{|c|c|c|c|}
\hline \multicolumn{4}{|l|}{ Reaction temperature } \\
\hline$R_{1}$ & $225^{\circ} \mathrm{C}$. & LHSV & $\begin{array}{c}1 \text { liter/liter, } \\
\text { hour }\end{array}$ \\
\hline$R_{2}$ & $200^{\circ} \mathrm{C}$. & GHSV & $\begin{array}{l}2.5 \text { liters/liter } \\
\text { hour }\end{array}$ \\
\hline $\begin{array}{l}\text { Reaction pressure } \\
\text { Sucrose concentration }\end{array}$ & $\begin{array}{l}200 \mathrm{~atm} . \\
0.29 \mathrm{kmole}^{-3} \\
\text { meter }^{-3}\end{array}$ & $\mathrm{Ca}(\mathrm{OH})_{2}$ & $\begin{array}{l}2 \text { wt. } \% \\
\text { Based on } \\
\quad \text { sucrose }\end{array}$ \\
\hline
\end{tabular}

Table II. Reaction Product Composition Formed during Continuous Catalytic Hydrogenolysis of Sucrose in a Cascade of Two CSTR's

\begin{tabular}{|c|c|c|c|}
\hline Components & $\begin{array}{c}\text { Weight } \\
\%\end{array}$ & Components & $\begin{array}{c}\text { Weight } \\
\%\end{array}$ \\
\hline thylene glycol & 15.6 & Methyl-D-fructofuranosides & 4.9 \\
\hline ropane-1,2-diol & 17.9 & Dehydrated hexitols & 1.8 \\
\hline Slycerol & 31.3 & Hexitols & 16.1 \\
\hline etritols & 4.9 & Unknown & 4.8 \\
\hline entitols & 2.7 & & $\overline{100.0}$ \\
\hline
\end{tabular}

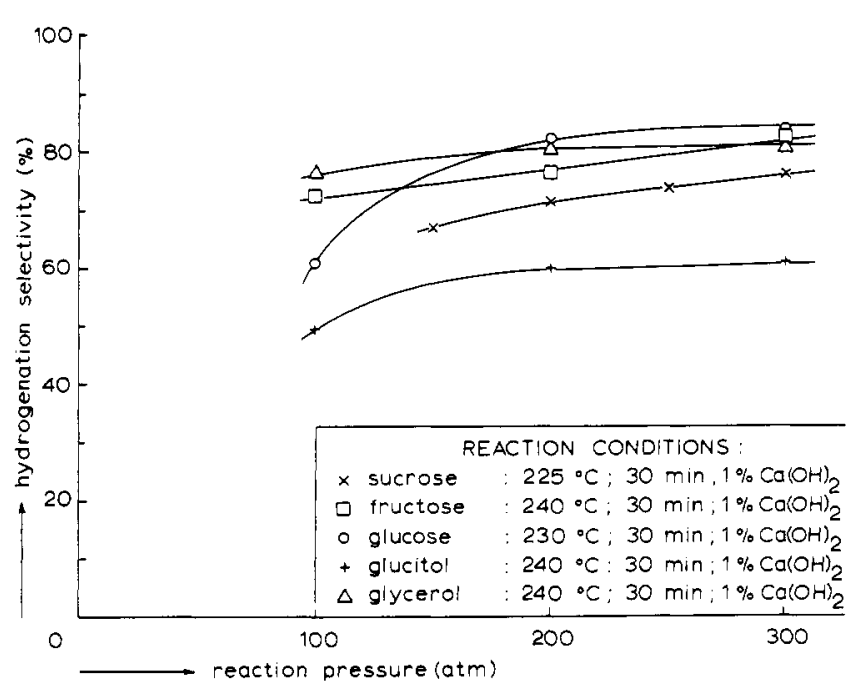

Figure 3. Influence of reaction pressure on hydrogenation selectivity $H S$ in a series of batch experiments 


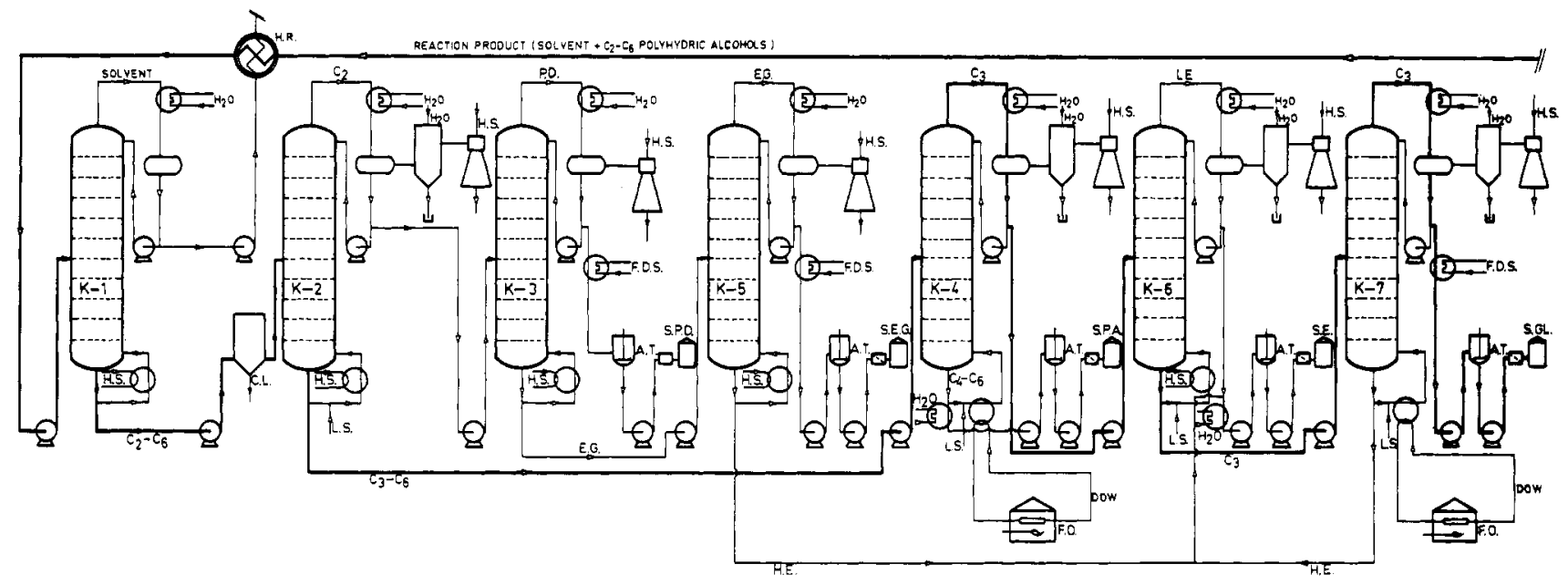

Figure 4. Distillation section for separation and purification of hydrogenolysis product

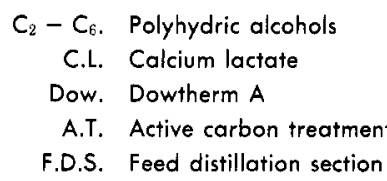

F.O. Fuel oil

H.S. High pressure steam

L.S. Low pressure steam

$K_{1}-K_{7}$. Distillation columns

S.E. Storage light and heavy ends

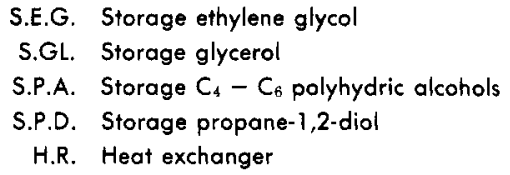

H.R. Heat exchanger

ride; from propylene via allyl chloride with simultaneous production of epichlorohydrin; and from propylene via acrolein.

For this study Driessen assumed a plant producing 30,000 tons of glycerol. Figure 4 shows the separation and purification of the hydrogenolysis product. Capital investments of all four processes have been calculated according to the "functional-unit" method of Zevnik and Buchanan (1963). This method, applied to the sucrosebased process, indicates a capital investment of $\$ 21.4 \times$ $10^{6}$.

The economic estimates prove that the main disadvantage of the present hydrogenolysis process is its relatively poor selectivity for glycerol formation. The economics of the process are largely determined by the sales potential of the by-products. One can assume that ethylene glycol is sold as antifreeze, propane-1,2-diol is used in food chemistry, and the $\mathrm{C}_{4}-\mathrm{C}_{6}$ polyhydric alcohols could be used as humectants. This marketing problem, however, poses subjects for further studies.

\section{Nomenclature}

$$
\begin{aligned}
C_{\mathrm{H}_{2}}= & \begin{array}{c}
\text { solubility of hydrogen in solvent, kmoles } \\
\text { meter }^{-3}
\end{array} \\
\mathrm{CP}= & \begin{array}{c}
\text { cleavage percentage, ratio of (glycerol }+ \\
\text { propane-1,2-diol + ethylene glycol + tetritol) }
\end{array} \\
& \text { to (hexitol }+ \text { glycerol + propane-1,2-diol + } \\
& \text { ethylene glycol + tetritol) content, } \%
\end{aligned}
$$

$\mathrm{CSTR}=$ continuous stirred tank reactor

$\mathrm{HS}=$ hydrogenation selectivity, ratio of (glycerol) to (glycerol + propane-1,2-diol) content, \%

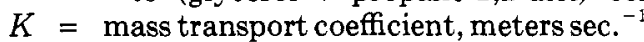
$N=\begin{gathered}\text { "over-all" } \\ \text { sec. }\end{gathered}$

$S=$ specific interfacial area of gas bubbles, meters ${ }^{2}$ meter ${ }^{-3}$

$\mathrm{TR}=$ tubular reactor

$z=$ relative saturation of solvent

\section{Literafure Cited}

Atlas Chemical Industries, Inc., Belg. Patent 635,207 (Jan. $20,1964)$.

Driessen, A. J., "Technical and Economic Evaluation of Catalytic Hydrogenolysis of Sucrose to Glycerol," Internal Report, Technological University Twente, 1968. Inventa A. G., Swiss Patent 423,738 (May 13, 1967). Inventa A. G., U.S. Patent 3,030,429 (April 17, 1962).

Van Ling, G., Ph.D. thesis, Technological University Twente, p. 83, 1967.

Van Ling, G., Ruijterman, C., Vlugter, J. C., Carbohydrate Res. 4, 380 (1967).

Van Ling, G., Vlugter, J. C., J. Appl. Chem. (London) 19, 43 (1969).

Zevnik, F. C., Buchanan, R. L., Chem. Eng. Progr. 59 (2), 70 (1963).

RECEIVED for review March 14, 1969 ACCEPTED October 24, 1969 